\title{
ASO Author Reflection: Learning Curves in Robotic Partial Nephrectomy-Not Only the Surgeon Counts
}

\author{
Philip Zeuschner, $\mathrm{MD}^{\mathbf{1}}$ (1) , Matthias Saar, $\mathrm{MD}^{1}$, and Martin Janssen, $\mathrm{MD}^{\mathbf{1 , 2}}$ \\ ${ }^{1}$ Department of Urology and Pediatric Urology, Saarland University, Homburg/Saar, Germany; ${ }^{2}$ Department of Urology \\ and Pediatric Urology, University Hospital of Munster, Munster, Germany
}

\section{PAST}

Robot-assisted partial nephrectomy (RAPN) has rapidly evolved into a standard technique in high-volume centers. To improve surgical outcomes, especially the learning curve of the robotic surgeon has extensively been analyzed so far. ${ }^{1}$ Furthermore, the annual caseload has been linked with better outcomes, referring to the learning curve of a department. ${ }^{2}$ However, data about the role of the bedside assistant is scarce and inconclusive. ${ }^{3}$ For this reason, we performed a comparative analysis to assess the impact of the learning curve of the department, surgeon, and bedside assistant, as well as of patient-related factors on perioperative outcomes of RAPN. ${ }^{4}$

\section{PRESENT}

Our first 500 transperitoneal RAPN were retrospectively analyzed. The experience "EXP" was defined as the current number of RAPNs conducted by either (1) the department, (2) the surgeon, or (3) the assistant. In multiple regression analysis, not only EXP of the surgeon and EXP of the department, but also EXP of the bedside assistant had a significant impact on perioperative outcomes. Higher EXP of the assistant was linked to shorter operating times,

Matthias Saar and Martin Janssen these authors contributed equally to this work.

(C) The Author(s) 2020

First Received: 20 June 2020

Accepted: 27 June 2020;

Published Online: 22 July 2020

P. Zeuschner, MD

e-mail: philip.zeuschner@uks.eu lower conversion, and higher success rates (defined as MIC: positive surgical margin, warm ischemia time, complications). Consequently, the impact of the bed-side assistant in RAPN has clearly been underestimated so far. Tumor complexity (PADUA score) impacted most perioperative outcome parameters and was thereby the most important patient-related factor. Perioperative outcomes significantly improved with EXP $>100$ for the department, EXP $>35$ for the surgeon, and EXP $>15$ for the assistant.

\section{FUTURE}

Although the fundamental need for bedside assistants in robotic surgery has been questioned recently, the complexity of robotic partial nephrectomy renders all participants of RAPN highly important. Training strategies in robotic surgery should not only focus on the surgeon but also on the department and bed-side assistants, which is currently clearly underdeveloped for RAPN.

ACKNOWLEDGEMENTS Open Access funding provided by Projekt DEAL.

DISCLOSURE There are no conflicts of interest and no disclosures to declare.

OPEN ACCESS This article is licensed under a Creative Commons Attribution 4.0 International License, which permits use, sharing, adaptation, distribution and reproduction in any medium or format, as long as you give appropriate credit to the original author(s) and the source, provide a link to the Creative Commons licence, and indicate if changes were made. The images or other third party material in this article are included in the article's Creative Commons licence, unless indicated otherwise in a credit line to the material. If material is not included in the article's Creative Commons licence and your intended use is not permitted by statutory regulation or exceeds the permitted use, you will need to obtain permission directly from the copyright holder. To view a copy of this licence, visit http://creativecommons. org/licenses/by/4.0/. 


\section{REFERENCES}

1. Mottrie A, De Naeyer G, Schatteman P, Carpentier P, Sangalli M, Ficarra V. Impact of the learning curve on perioperative outcomes in patients who underwent robotic partial nephrectomy for parenchymal renal tumours. Eur Urol. 2010;58(1):127-32.

2. Arora S, Keeley J, Pucheril D, Menon M, Rogers CG. What is the hospital volume threshold to optimize inpatient complication rate after partial nephrectomy? Urol Oncol. May 142018.

3. Potretzke AM, Knight BA, Brockman JA, et al. The role of the assistant during robot-assisted partial nephrectomy: does experience matter? J Robot Surg. 2016;10(2):129-34.
4. Zeuschner P, Meyer I, Siemer S, Stoeckle M, Wagenpfeil G, Wagenpfeil S, Saar M, Janssen M. Three different learning curves have an independent impact on perioperative outcomes after robotic partial nephrectomy - a comparative analysis. Ann Surg Oncol. 2020. https://doi.org/10.1245/s10434-020-08856-1.

Publisher's Note Springer Nature remains neutral with regard to jurisdictional claims in published maps and institutional affiliations. 